\title{
Toward a Competitive Process Intensification: A New Generation of Heat Exchanger-Reactors
}

\author{
P. Tochon', R. Couturier' ', Z. Anxionnaz', S. Lomel'2, H. Runser 3 , F. Picard' 3 , A. Colin 3 , \\ C. Gourdon ${ }^{4}$, M. Cabassud ${ }^{4}$, H. Peerhossaini ${ }^{5}$, D. Della Valle ${ }^{5}$ and T. Lemenand ${ }^{5}$ \\ 1 CEA LITEN, 17 avenue des Martyrs, 38054 Grenoble Cedex 9 - France \\ 2 Rhodia, 85 rue des Frères Perret, BP 62, 69192 Saint Fons Cedex - France \\ 3 Fives Cryo, 25 bis rue du Fort, BP 87, 88194 Golbey Cedex - France \\ 4 Université de Toulouse, Laboratoire de Génie Chimique, UMR 5503 CNRS/UPS/INPT, 4 allée E. Monso, BP 44362, \\ 31432 Toulouse Cedex 4 - France \\ 5 Laboratoire de Thermocinétique de Nantes, CNRS UMR 6607, rue Christian Pauc, BP 50609, 44306 Nantes - France \\ e-mail: patrice.tochon@cea.fr - raphael.couturier@cea.fr - zoe.anxionnaz@cea.fr - sebastien.lomel@eu.rhodia.com \\ helene.runser@fivesgroup.com - florian.picard@fivesgroup.com - alice.niclou@fivesgroup.com - christophe.gourdon@ensiacet.fr \\ michel.cabassud@ensiacet.fr - hassan.peerhossaini@univ-nantes.fr - dominique.dellavalle@oniris-nantes.fr - thierry.lemenand@univ-nantes.fr
}

Résumé - Vers une intensification des procédés économiquement viable : une nouvelle génération de réacteur-échangeur de chaleur - L'intensification des procédés (IP) constitue une des préoccupations majeures de l'industrie chimique. Parmi les nombreuses options possibles pour intensifier un procédé, lorsque le sujet concerne la sélectivité et l'échange thermique, la transposition d'un réacteur discontinu à un réacteur tubulaire continu paraît une bonne alternative. Dans ce contexte, le projet de R\&D RAPIC consiste à développer un composant innovant à bas coût (environ $10 \mathrm{~kg} / \mathrm{heure}$ ). Ce projet porte sur la phase de conception, du niveau local au niveau global, et sur la phase de tests, depuis les maquettes élémentaires jusqu'aux essais pilote. Cet article propose une description détaillée de ce projet de recherche et présente les principaux résultats obtenus sur la définition et la spécification du canal de réaction, ainsi que les premières maquettes simples.

\begin{abstract}
Toward a Competitive Process Intensification: A New Generation of Heat ExchangerReactors - Process Intensification (PI) in chemical production is a major concern of chemical manufacturers. Among the numerous options to intensify a process, the transposition from a batch reactor to a continuous plug flow reactor is a good alternative when the selectivity and the thermal exchange are an issue. In this context, the RAPIC R\&D project aims to develop an innovative low-cost component (in the $10 \mathrm{~kg} / \mathrm{h}$ range). This project deals with the design from the local to the global scale and with testing, from elementary mock-ups to pilot scale. The present paper gives a detailed description of this research project and presents the main results on specification and definition of the reaction channel and the first simple mock-ups.
\end{abstract}




\section{INTRODUCTION}

Process Intensification (PI) methodology, introduced in the 1980s, was recently defined [1] as "any chemical engineering development that leads to a substantially smaller, safer, cleaner and more energy-efficient technology". Among the numerous options to intensify a process, the transposition from a batch reactor to a continuous plug flow reactor is a good alternative when the selectivity and the thermal exchange are an issue: this case is illustrated in this study through the concept of multifunctional heat exchanger/reactor $[2,5]$. Many benefits are expected such as waste reduction, energy and raw materials savings, yield and selectivity increase, and cost reduction. Despite these benefits, to date only a few intensified processes are in industrial operation. Nevertheless, typical academic studies [3-9] of multifunctional heat exchanger-reactors in the literature report the large potential of this technology. The relatively slow transfer to industry is presumably linked to many factors, among them the lack of successful industrial demonstrations.

The RAPIC project focuses on the implementation in industry of intensified continuous unit and aims to be polyvalent and flexible (batch processes as well), robust (not too sensitive to varying conditions) and low-cost (crucial for process industrialization). The present paper details this research project and presents the main results on specification and definition of the reaction channel and the first elementary mock-ups.

\section{RAPIC PROJECT DESCRIPTION}

\subsection{Main Objectives}

The RAPIC R\&D project, started in December 2007 and funded for three years by the French National Research
Agency (ANR) with a financial support from Axelera (chemistry environment competitive cluster), aims to develop an innovative but low-cost component in the $10 \mathrm{~kg} / \mathrm{h}$ range. It is original in that it must not only comply with the implementation constraints of exothermal reactions, but also be as close as possible to maturing technologies in the heatexchanger sector by adapting them to reactive media and by respecting the cost imperatives imposed by the market. In principle, the plate reactor is composed of alternate (sandwich) coolant and reaction circuits (Fig. 1). Circuits are brazed in order to ensure good thermal contact. Thus, using enhanced plate-fin geometry available on the market, the RAPIC plate reactor has very high heat-transfer ability to ensure excellent thermal control of the reaction.

We plan to use Hot Isostatic Pressing (HIP) fabrication technology for the reaction channels so that we can produce modules with different materials (copper, stainless steel) placed around the reaction channels for efficient management of exothermal effects [10]. The complex geometries needed for Process Intensification are obtained by assembling machined metallic plates or bent tubes embedded in sintered metal powders. Large industrial HIP facilities available today can produce low-cost components with enhanced thermal performance.

\subsection{Project Organization}

Over its three years, the RAPIC project will deal with design from the local to the global scale and experimentation from elementary mock-ups to pilot-scale systems. Five main tasks are involved $\left(T_{\mathrm{o}}=\right.$ December 2007):

- specification of the plate reactor by the end user in terms of performance level and acceptable price $\left(T_{0} \Rightarrow T_{0}+\right.$ 3 months);

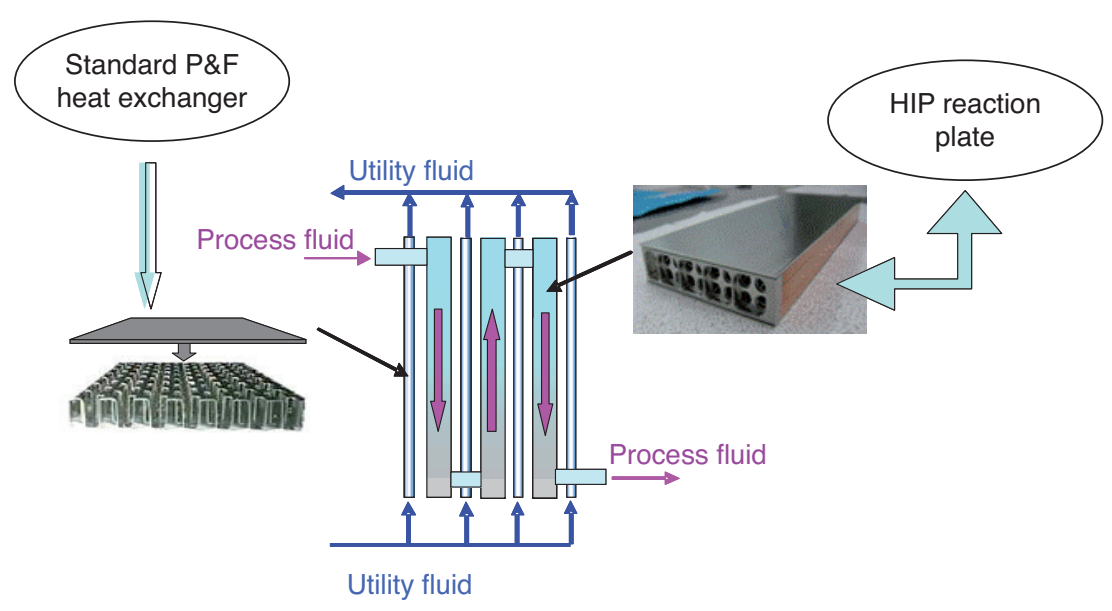

Figure 1

Schematic of RAPIC plate reactor. 
- definition of the reaction channel, based on numerical simulation and analytical tests $\left(T_{\mathrm{o}}+3 \Rightarrow T_{\mathrm{o}}+18\right.$ months);

- manufacture (by traditional or innovative techniques) and testing (thermo-hydraulic and micromixing) of plate modules designed for reaction $\left(T_{0}+3\right.$ months $\Rightarrow T_{0}+$ 18 months);

- manufacture and test of two prototypes (1-10 L/h $\left.\mathrm{h}^{-1}\right)$; several representative exothermal reactions will be tested $\left(T_{\mathrm{o}}+18\right.$ months $\Rightarrow T_{\mathrm{o}}+36$ months);

- market assessment and dissemination $\left(T_{\mathrm{o}}+33\right.$ months $\Rightarrow$ $T_{\mathrm{o}}+36$ months).

Since the present paper summarizes work in the first project year, only tasks 1,2 and 3 are detailed.

\subsection{Partnerships}

The teams in the RAPIC project are highly complementary (Fig. 2). Indeed, one end-user (Rhodia Chemicals) and one heat-exchanger manufacturer (Fives Cryo) are involved to ensure the industrial orientation of the work. In addition, French laboratories active in basic research on process engineering (LGC) and thermal-hydraulic engineering (LTN) are involved. The Atomic Energy Commission (CEA/LITEN) is handling project coordination, component design, and manufacture of the reaction plates using HIP technology.

The involvement in RAPIC of a leading chemical group (Rhodia) as well as a parts manufacturer (Fives Cryo) desiring to diversify its industrial activities constitutes a driving force and ensures the future industrial application of the work.

\section{SPECIFICATIONS}

The specification, in terms of the chemical reaction target, has been defined by Rhodia. The reaction is a homogeneous

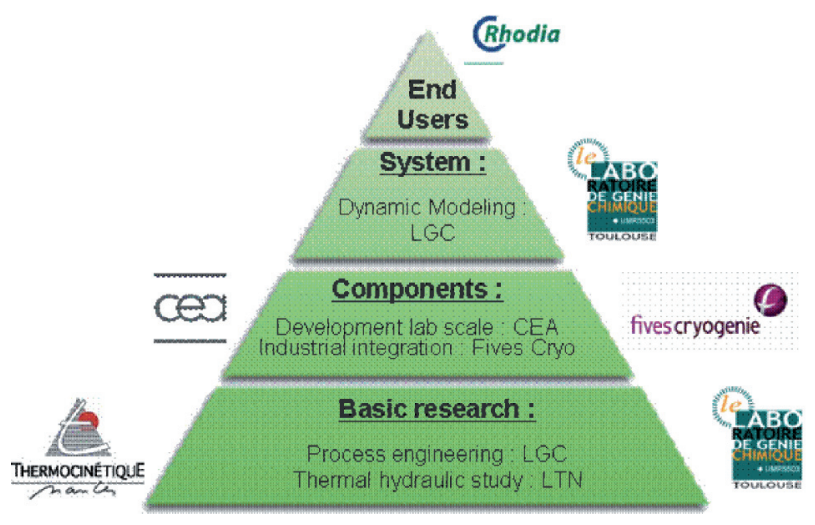

Figure 2

Role of partners in RAPIC project. exothermic reaction in liquid phase, with an adiabatic temperature rise of $200^{\circ} \mathrm{C}$. It is carried out at $100^{\circ} \mathrm{C}$ and under atmospheric pressure due to the design features of the batch reactor. However, the pressure is not a sensitive parameter to run the reaction. This is a fast reaction, with a residence time of 2-3 minutes. The reactor must be as isothermal as possible, with a maximum temperature rise of $10^{\circ} \mathrm{C}$. Figure 3 gives the required reactor volume as a function of volumetric heattransfer performance and coolant temperature (the chosen coolant throughput allows overcoming any heat exchange limitation in the "coolant side").

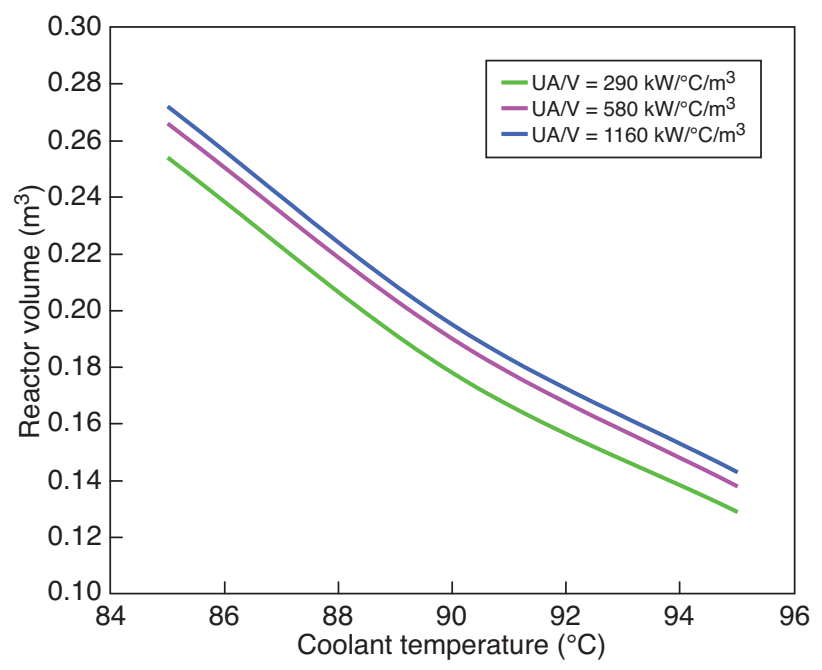

Figure 3

Specified operating conditions.

Three main sizes have been defined as production targets for the project:

- elementary scale: $1 \mathrm{~L} \cdot \mathrm{h}^{-1}$,

- laboratory scale: $10 \mathrm{~L} \cdot \mathrm{h}^{-1}$,

- pilot scale: from hundreds of $L \cdot h^{-1}$ up to few cubic meters $/ h^{-1}$. Only laboratory-scale units will be constructed and tested within the RAPIC project. However, extrapolation to the pilot scale is included in the choice of concept and geometry.

A detailed economic analysis made by Rhodia for industrial chemical production of $6 \mathrm{kTs} \cdot \mathrm{y}^{-1}$ is based on a methodology for transferring batch to continuous reaction. For this estimate, the reactor investment assumes a price equal to that of a $27 \mathrm{~m}^{3}$ semi-batch technology. In addition, the analysis also includes modification of the process environment, such as upstream and downstream storage tanks (larger for batch process), injection simplification, and data measurement and acquisition systems. Using these assumptions, the overall investment cost of a batch unit for $6 \mathrm{kT} \cdot \mathrm{y}^{-1}$ has been 
estimated. For a continuous process, in order to achieve the same investment cost, an acceptable price level for the RAPIC plate reactor has been set.

In term of manufacturing costs, we assume in a first time that the transposition from a batch process to a continuous process does not allow saving money: to meet the economical stakes, the investment cost is the key economical parameter to manage. However, this assumption on manufacturing costs is very pessimistic. Indeed, the following potential gains could be expected in a continuous configuration:

- energy savings: less thermal losses due to the smaller volume;

- raw materials savings: if selectivity issues are encountered in the batch process, higher yield for the continuous reaction step are expected. Moreover, the investment costs decrease (fewer throughputs to treat) for the following separation and for the effluent treatment steps;

- decrease of fixed costs in terms of labour costs (less shifts to manage the process) and depreciation (proportional to the investment).

As a consequence, the acceptable price level set for the RAPIC plate reactor is the very lowest threshold and gives us a reasonable financial margin.

\section{FIRST PLATE REACTOR CONCEPT}

\subsection{Simplified Modeling}

Using simplified thermal-hydraulic modeling, a pre-sizing of a first plate reactor based on the specification has been made. This sizing is based on:

- the transference of CEA's know-how in nuclear fusion activity [10] to the reaction part: integrating straight stainless steel tubes $(8 / 10 \mathrm{~mm})$ into a thermal conducting copper matrix (Fig. 4). The elementary plate size was determined by the availability of HIP vessels: $1.25 \mathrm{~m}$ long, $0.8 \mathrm{~m}$ wide;

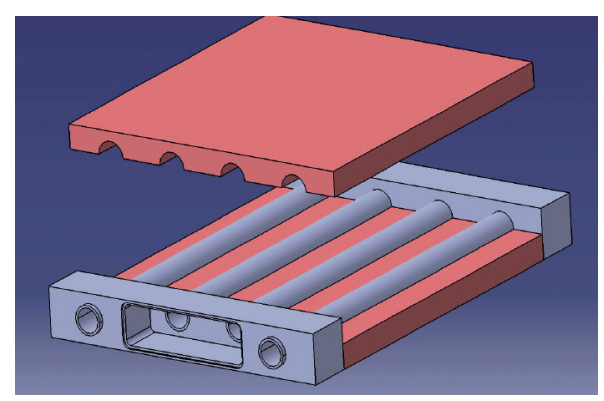

Figure 4

Schematic of the first design of RAPIC reaction plate (grey - stainless steel; orange - copper).
- the use of standard straight and perforated fins $(4 \mathrm{~mm}$ high, $0.15 \mathrm{~mm}$ thick) on the utility side in order to improve reactor coolant capacity.

Thus, in order to reach the predefined specifications, the full-size plate reactor has the following characteristics:

- 25 reaction plates ( 2 passes) in parallel, hence 50 plates surrounded by 51 utility plates with straight and perforated strip fins;

- each plate includes 60 tubes $(8 / 10 \mathrm{~mm})$, with twisted tape inserts inside and external turning boxes;

- plates are mainly copper, with stainless steel as the external skin (container). The final thickness of each reaction plate is around $20 \mathrm{~mm}$.

The final component has external dimensions $800 \mathrm{~mm} \times$ $1440 \mathrm{~mm} \times 1250 \mathrm{~mm}$ and volume $1.44 \mathrm{~m}^{3}$.

With this design, we reach a heat transfer capability of $580 \mathrm{~kW} \cdot \mathrm{m}^{-3} \cdot \mathrm{K}^{-1}$ and a pressure drop of 7 bars; the design thus meets both the required residence time and heat transfer goals. It is also a feasible technological solution.

\subsection{Full Prototype Cost Estimation}

A precise cost estimate has been made for the above design:

- utility plate using offset strip fins: $22 \%$ of the total cost;

- reaction plates: $78 \%$ of the total cost with $50 \%$ for materials procurement and machining.

Therefore, this first design has an overall cost equal to the one of an equivalent batch technology for a $6 \mathrm{kT} \cdot \mathrm{y}^{-1}$ production. This cost could be significantly reduced by enhanced design, which could lead to more compact geometries, and by manufacturing technology improvements. In any case, however, the RAPIC project has a realistic basis.

\subsection{First Elementary Mock-ups}

The objective of the first mock-up is to demonstrate that the design criteria selected for RAPIC lead to a low cost reaction plate by the choice of a mature manufacturing process and a simple geometry. The mock-up size is around $320 \times 130 \times$ $25 \mathrm{~mm}$, with two levels of tubes to increase compactness. The performance of the mock-up will be measured in terms of heat transfer capacity, macro and micro mixing efficiency.

As shown in Figure 5, the mock-up is made of straight stainless steel tubes inserted in a copper matrix. Internal stainless steel swirls are placed into the tubes to enhance heat transfer and mixing. Tubes are placed between copper plates grooved by milling. The distribution and turning over of the fluid is ensured by two machined stainless steel turning boxes.

Once the tubes are welded to turning boxes and inserted between copper, all parts are placed into a metallic container that is sealed and degassed under vacuum. Hot Isostatic Pressing (typically under $1000^{\circ} \mathrm{C} / 1000 \mathrm{bar} / 1 \mathrm{~h}$ ) is then 


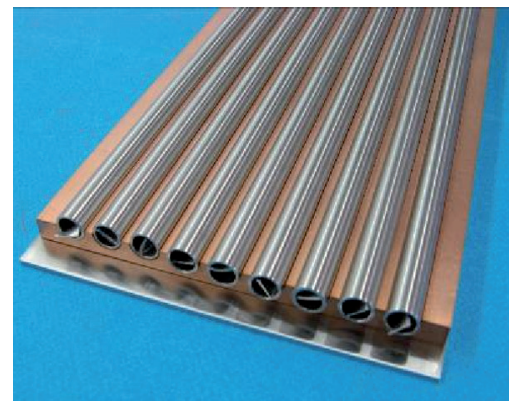

a)

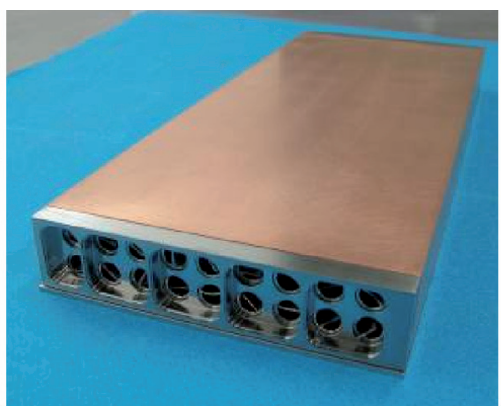

b)

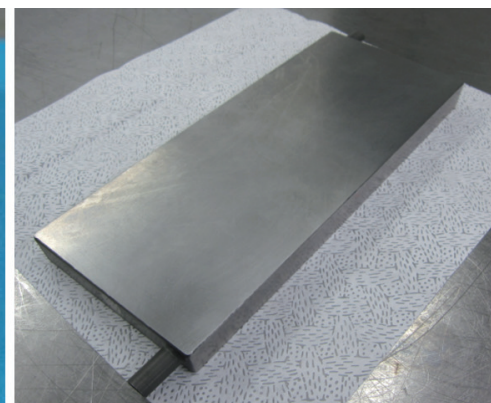

C)

Figure 5

Manufacturing steps for the first reaction plate mock up: a) tubes with internal swirls are placed between copper plates, b) turning and distribution boxes are welded to tube ends, c) mock up after HIP and final machining.

applied to weld all materials (tubes to distribution boxes, tubes to copper, copper to the container) by diffusion bonding. A final machining is performed on top and lower surfaces to ensure the proper flatness.

\section{STRATEGY FOR REACTION CHANNEL OPTIMIZATION}

So far, a feasible concept has been designed and manufactured that meets all the predetermined specifications, including the price. However, this design is based on the use of straight tubes with inserts, which is not globally optimal. Thus design work has been lead in order to develop a more efficient, realizable and up-scalable geometry [11]. Some orientations, based on enhanced design, have been considered:

- modification of channel cross-section shape (circular, square, rectangular),

- channels structural geometries (two-dimensional waves, three-dimensional geometries, etc.).

Hence, the definition of an improved reaction plate pattern was based on a systematic multiscale analysis, using analytical, experiments or simulation tools (Fig. 6). Thus, a second plate-reactor concept has been defined.

Five mock-up designs, involving different channels' shapes and fabrication technologies have been considered. They have been ranked according to their technical and fabrication feasibility. The optimum mock-up (Fig. 7), chosen in function of the technico-economical criteria, and the reference one (Fig. 5) have been characterized in terms of thermal performances and hydrodynamic behaviour.

The wavy channel is of rectangular cross section $(2 \mathrm{~mm} \times$ $4 \mathrm{~mm}$ ) and is machined with through-laser. Each plate is made of stainless steel of $2 \mathrm{~mm}$ thick (closing plates) or $4 \mathrm{~mm}$ thick (machined plate) and the overall size of the mock-up is $0.198 \times 0.095 \times 0.008 \mathrm{~m}$. The volume of fluid in the wavy channel is of $17.6 \mathrm{~mL}$.

\section{CHARACTERIZATION RESULTS}

The experimental characterizations concern the thermal performances, the Residence Time Distribution (RTD) and the pressure drops.

\subsection{Pressure Drops}

The general expression of pressure drop is written:

$$
\Delta P=4 \cdot f \cdot \frac{L}{d_{h}} \cdot \mathrm{c} \cdot \frac{u^{2}}{2}
$$

with $\rho$ the density of the fluid, $u$ its velocity; $L$ and $d_{h}$ respectively the length and the hydraulic diameter of the channel and $f$, the friction factor which is characteristic of the size and of the geometry of the channel. The evolution of the friction factor with the Reynolds number is shown in Figure 8.

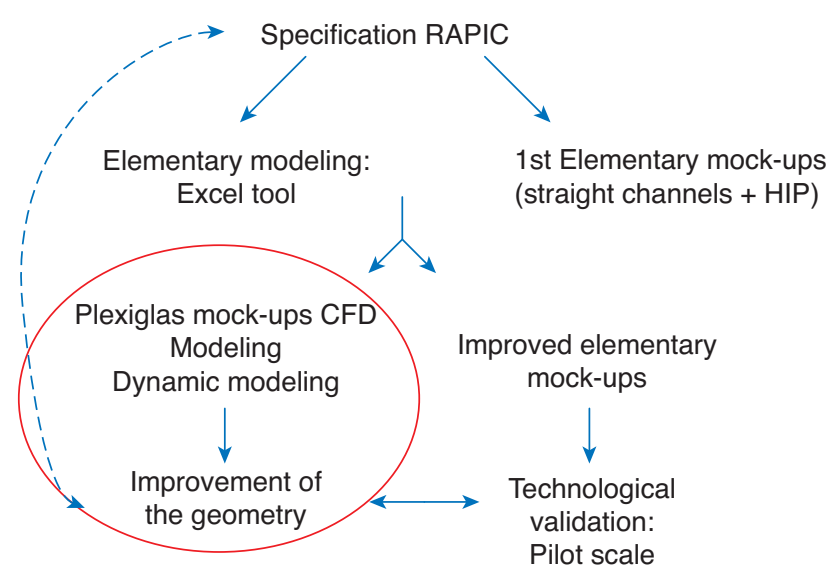

Figure 6

Strategy for developing improved plate reactor geometry. 


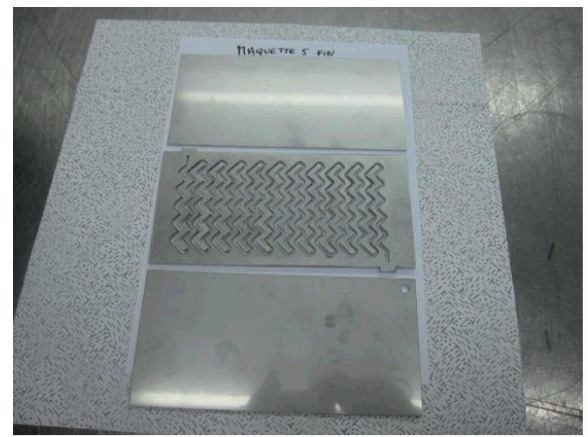

a)

Figure 7

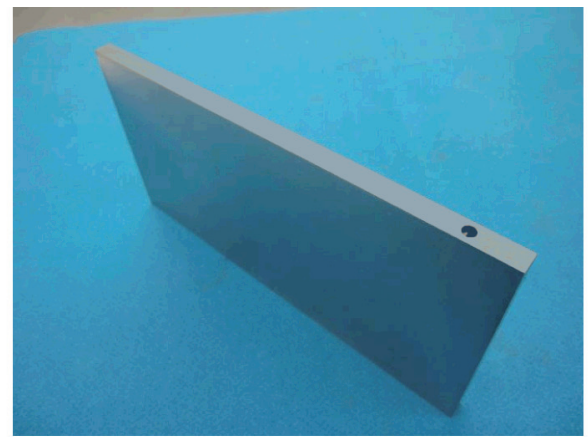

b)

Manufacturing step for the second reaction plate mock-up: a) wavy channel inserted between two stainless steel, b) mock-up after HIP and final machining.

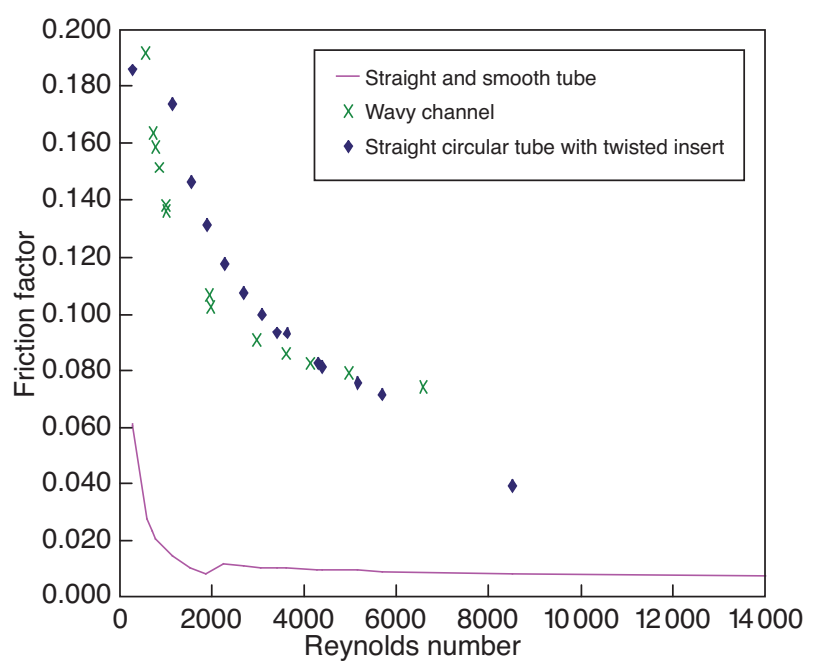

Figure 8

Friction factor versus Reynolds number, experiments with water at $25^{\circ} \mathrm{C}$.

The evolution of the friction factor versus the Reynolds number is similar in the two mock-ups. However, it should be noticed that the characteristic size of each channel is different ( 8 and $2.7 \mathrm{~mm}$ ) and so is the utilization field in terms of flow rate (respectively 100 and $10 \mathrm{~L}^{-1} \mathrm{~h}^{-1}$ ). As a consequence, pressure drops will be different in each mockup as shown in Table 1.

\section{TABLE 1}

Pressure drops measured in each mock-up

\begin{tabular}{l|c|c|c|c}
\hline & $\begin{array}{c}\text { Flow rate } \\
\left(\mathrm{kg} \cdot \mathrm{h}^{-1}\right)\end{array}$ & $\begin{array}{c}\text { Fluid velocity } \\
\left(\mathrm{m} \cdot \mathrm{s}^{-1}\right)\end{array}$ & $\begin{array}{c}\text { Reynolds } \\
\text { number }\end{array}$ & $\begin{array}{c}\Delta P \\
\text { (mbar) }\end{array}$ \\
\hline $\begin{array}{l}\text { Straight tube } \\
\text { with twisted insert }\end{array}$ & 7 to 177 & 0.02 to 0.5 & 260 to 8510 & 0.5 to 70 \\
\hline Wavy channel & 3.6 to 49 & 0.13 to 1.7 & 550 to 10460 & 51 to 2421 \\
\hline
\end{tabular}

\subsection{Thermal Characterization}

Thermal study is based on experiments which aim at cooling the fluid flowing in the reaction plate mock-up. The fluid is distilled water heated at about $85^{\circ} \mathrm{C}$ whereas the cooling fluid is raw water at about $10^{\circ} \mathrm{C}$. For each experiment, the cooling flowrate is set to $6 \mathrm{~m}^{3} \cdot \mathrm{h}^{-1}$ whereas the process flowrate varies from 4 to $180 \mathrm{~L} \cdot \mathrm{h}^{-1}$. Four temperature sensors are set between the inlet and the outlet of the reaction plate and of the cooling system. To compare each geometry, the Nusselt number versus Reynolds number is plotted in Figure 10. The general expression of Nusselt number is written:

$$
N u=\frac{h d_{h}}{\lambda}=a R e^{b} \operatorname{Pr}^{0.33}
$$

with $\operatorname{Pr}=\frac{C_{p} \mu}{\pi}$

$d_{h}, h, \lambda$ and $C_{p}$ are respectively the hydraulic diameter, the local heat transfer coefficient, the thermal conductivity and the heat capacity of the fluid.

First, from the experimental temperature measurements, the heat exchanged, $Q$, between the cooling fluid and the process one is calculated:

$$
Q=F C_{P} \Delta T
$$

$F$ and $\Delta T$ are respectively the process flow rate and the temperature difference between the reactor inlet and outlet.

Then, the global heat transfer coefficient, $U$, is estimated:

$$
U=\frac{Q}{A \Delta T_{m l}}
$$

$A$ is the specific exchange area between the two fluids and $\Delta T_{m l}$ is the logarithmic mean of temperature. The global heat transfer coefficient is also written as follows:

$$
\frac{1}{U A}=\frac{1}{h_{p} A_{p}}+\frac{e}{\lambda}+\frac{1}{h_{u} A_{u}}
$$




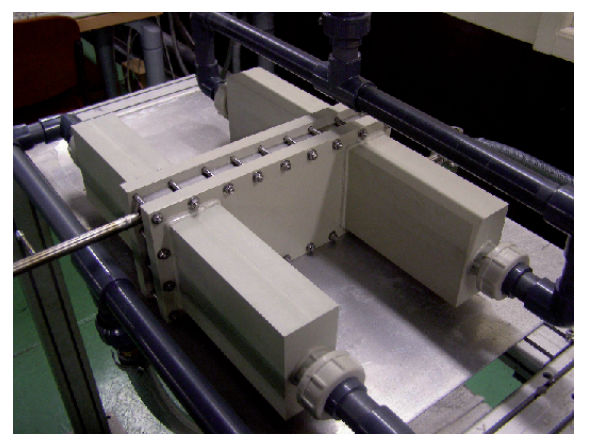

Figure 9

Cooling baffles used to the thermal characterization.

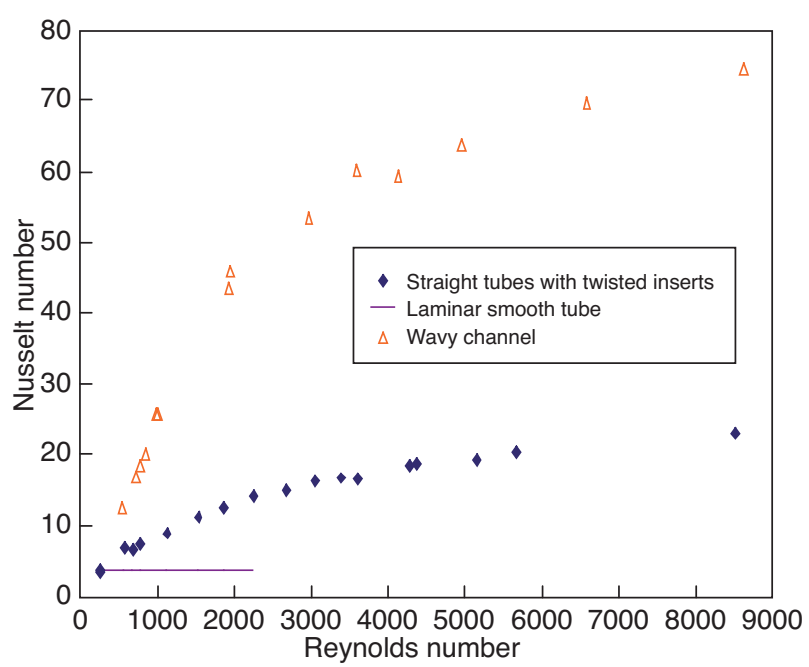

Figure 10

Nusselt number versus Reynolds number for each mock-up.

$h_{p}$ and $h_{u}$ are respectively the process and utility local heat transfer coefficients. $A_{p}$ and $A_{u}$ are respectively the specific exchange areas on process and utility sides. $e$ is the material thickness between process and utility fluids and $\lambda$ is the thermal conductivity of the material.

For each mock-up (straight tubes with twisted inserts and wavy channel), the cooling is made with two cooling baffles on both sides of the characterized mock-up. This is illustrated in Figure 9.

The cooling flow rate is set to $6 \mathrm{~m}^{3} \mathrm{~h}^{-1}$. It corresponds to a Reynolds number equal to 10500 in the straight tube mockup and equal to 18000 in the wavy channel mock-up. Since the flow is turbulent and the geometrical dimensions are well-known (rectangular flat channel), the utility local heat transfer coefficient can be estimated from the Colburn correlation:

$$
N u=0.023 \operatorname{Re}^{0.8} \operatorname{Pr}^{1 / 3}
$$

For $10^{4}<\operatorname{Re}<1.2 \times 10^{5}$ and $0.5<\operatorname{Pr}<100$.

From Equation (2), it is then possible to know the local heat transfer coefficient on utility side, $h_{u}$. The local heat transfer coefficient on process side is thus known from Equation (5) and finally, Equation (2) allows to calculate the Nusselt number on process side. It is plotted versus Reynolds number in Figure 10.

The experimental results show that the heat transfer in the second mock-up (wavy channel) is until 3 times more efficient than in the straight tubes filled with a twisted insert. Moreover, the characteristic curve of this mock-up seems to stabilize for high Reynolds number. This may be due to the conductive effects which start to limit the heat transfer between the cooling fluid and the other one around $R e=5000$.

\subsection{Residence Time Distribution (RTD)}

RTD experiments have been carried out in order to characterize the hydrodynamic behaviour in the two mock-ups. A conductimetric technique has been used. Two measuring probes are set up at the inlet and at the outlet of the mock-up. Each experiment has been performed at room temperature with a flow rate varying from 10 to $200 \mathrm{~L} \cdot \mathrm{h}^{-1}$ (Reynolds number ranges from 1000 to 11000 ). The experimental RTD has been modelled by an axial dispersion model characterized by the Peclet number:

$$
P e=\frac{u \cdot L}{D}
$$

$u, L$ and $D$ are respectively the flow velocity, the channel length and the dispersion coefficient. The higher the Peclet number is, the more the flow behaves like a plug flow, which is necessary to perform safely and efficiently chemical syntheses. Numerical results are given in Table 2 .

TABLE 2

Peclet number and residence time in each mock-up

\begin{tabular}{l|r|r|r|c|l}
\hline & $\begin{array}{c}\text { Flow rate } \\
\left(\mathrm{L}^{-1}{ }^{-1}\right)\end{array}$ & $\begin{array}{c}\text { Reynolds } \\
\text { number }\end{array}$ & $\begin{array}{c}\text { Peclet } \\
\text { number }\end{array}$ & $\begin{array}{c}\text { Difference } \\
\text { between } \\
\text { theoretical and } \\
\text { measured } \\
\text { residence } \\
\text { time (\%) }\end{array}$ & $\begin{array}{l}\text { Correlation } \\
\text { coefficient }\end{array}$ \\
\hline $\begin{array}{l}\text { Straight tube } \\
\text { with twisted }\end{array}$ & 20.8 & 1040 & 108 & 14 & 0.96 \\
insert & 206.8 & 4400 & 370 & 8 & 0.97 \\
\hline $\begin{array}{l}\text { Wavy } \\
\text { channel }\end{array}$ & 9.4 & 8880 & 426 & 3 & 0.98 \\
\hline
\end{tabular}

For each geometry the Peclet number is high enough, i.e. the residence time distributions are narrow enough to consider that the flow behaves like a quasi plug flow $(P e>50)$. This 


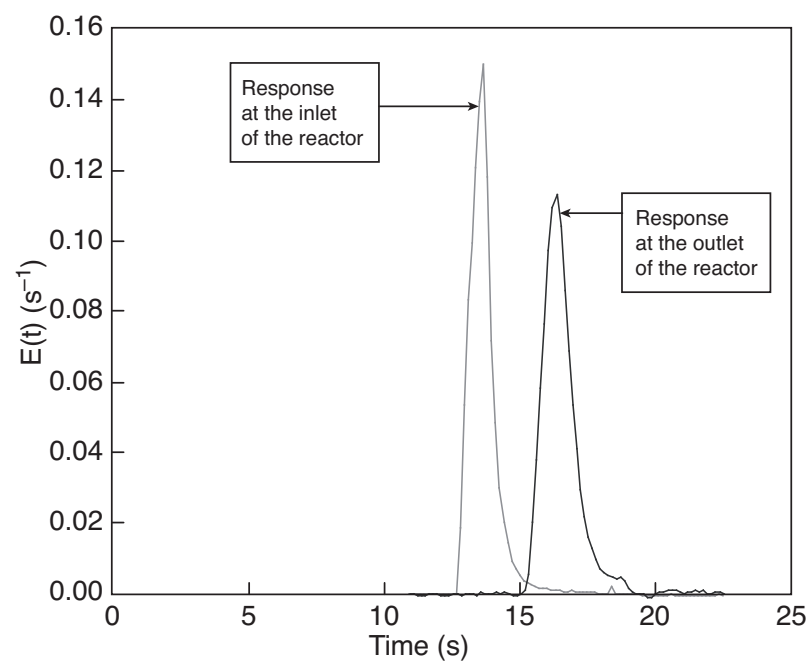

Figure 11

RTD graph in the wavy channel $(R e=4000-P e=102)$.

characteristic is necessary to make sure that there are no dead zones or by-passes that could lead to decreases of the reactor performances (yields, selectivity, etc.). Figure 11 shows the RTD experimental graph in the wavy channel mock-up.

\section{CONCLUSIONS AND FUTURE WORK}

The RAPIC R\&D project is at the middle of its third year. The first two reactor concepts have been successfully designed and manufactured and the results of the experimental characterizations are promising. The first design (straight tubes filled with twisted inserts) is very simple and fits all the predetermined specifications for the Rhodia application case, particularly the high flow rate request. The investment costs are equal to the ones of an equivalent batch reactor and potential gains are expected in terms of product manufacturing costs (energy and raw materials savings, decrease of fixed costs, etc.). The main barrier of this design remains the quite high pressure drops in the case of pressure dependent reactions.

In order to intensify heat and mass transfer and improve the compactness of the apparatus, a second design has been proposed. The channel geometry has been $2 \mathrm{D}$ structured (wavy channel) while technological options have been validated to allow a low-cost manufacture. The investment cost corresponds to $50 \%$ of a batch reactor process and additional gains are expected thanks to the transposition from batch to continuous process.

At the end of the RAPIC project, two prototypes (10-50 L $\left.\mathrm{h}^{-1}\right)$ will be available to test various chemical reactions and systems.

\section{REFERENCES}

Stankiewicz A.I., Moulijn J.A. (2000) Process intensification: transforming chemical engineering, Chem. Eng. Prog. 96, 22-34.

Thonon B., Tochon P. (2004) Compact multifunctional heat exchangers: a pathway to process intensification, in Re-Engineering the Chemical Processing Plant, Stankiewicz A., Moulijn J.A. (eds), Dekker.

Ferrouillat S., Tochon P., Garnier C., Peerhossaini H. (2006) Intensification of heat transfer and mixing in heat exchangerreactors by artificially generated streamwise vortices, Appl. Therm. Eng. 26, 1820-1829.

Ferrouillat S., Tochon P., Della Valle D., Peerhossaini H. (2006) Open loop thermal control of exothermal chemical reactions in a multifunctional heat exchanger, Int. J. Heat Mass Tran. 49, 2479-2490.

Anxionnaz Z., Cabassud M., Gourdon C., Tochon P. (2008) Heat exchanger/reactors (HEX reactors): concepts, technologies, state-ofthe-art, Chem. Eng. Process. 47, 2029-2050.

Anxionnaz Z., Cabassud M., Gourdon C., Tochon P. (2010) Transposition of an exothermic reaction from a batch reactor to an intensified continuous one, Heat Transfer Eng. 31, 9, 788-797.

Habchi C., Lemenand T., Della Valle D., Peerhossaini H. (2010) Alternating mixing tabs in multifunctional heat exchanger-reactor, Chem. Eng. Process. 49, 653-661.

Mohand Kaci H., Lemenand T., Della Valle D., Peerhossaini H. (2009) Effects of embedded streamwise vorticity on turbulent mixing, Chem. Eng. Process. 48, 1457-1474.

Mohand Kaci H., Habchi C., Lemenand T., Della Valle D., Peerhossaini H. (2010) Flow structure and heat transfer induced by embedded vorticity, Int. J. Heat Mass Transfer 53, 3575-3584.

Lorenzetto P., Peacock A., Bobin-vastra I., Briottet L., Bucci P., Dell Orco G., Roedig M., Sherlock P. (2006) EU R\&D on the ITER First wall, Fusion Eng. Design 81, 355-362.

Anxionnaz Z. (2009) Étude de l'influence de la géométrie des canaux sur les performances d'un échangeur/réacteur, PhD Thesis, Institut National Polytechnique de Toulouse.

Final manuscript received in June 2010 Published online in October 2010 